\title{
EFFECT OF INSULIN GLARGINE ON RECREATIONAL PHYSICAL ACTIVITY AND TV VIEWING: ANALYSIS OF THE RANDOMISED ORIGIN TRIAL
}

\section{Short title: insulin glargine and physical activity}

Tom Yates ${ }^{1,2}$, Melanie J Davies ${ }^{1,2}$, Hyejung Jung ${ }^{3}$ Jackie Bosch $^{3}$, Giatgen A Spinas ${ }^{4}$, Seamus Sreenan ${ }^{5}$, Patrick Commerford ${ }^{6}$, Hertzel C Gerstein ${ }^{7}$, ORGIN investigators*

1. Diabetes Research Centre, University of Leicester, Leicester General Hospital, Leicester, Leicestershire, LE5 4PW, United Kingdom.

2. National Institute for Health Research (NIHR) Leicester Biomedical Research Centre (BRC), University of Leicester, United Kingdom

3. Population Health Research Institute, McMaster University, Hamilton Health Sciences, Hamilton, Ontario, Canada

4. Division of Endocrinology, Diabetes and Clinical Nutrition, University Hospital Zurich, Zurich, Switzerland

5. 3U Diabetes, Department of Diabetes and Endocrinology, Royal College of Surgeons in Ireland, Connolly Hospital, Dublin, Ireland

6. Department of Medicine, University of Cape Town Observatory, Cape Town, South Africa

7. Department of Medicine and Population Health Research Institute, McMaster University and Hamilton Health Sciences, Hamilton, Ontario, Canada

Abstract word count: 205

Main text word count: 2786

Number of Tables: 3

Number of Figures: 0

Supplementary material: Supplemental Tables S1

Corresponding Author: Dr Thomas Yates, Leicester Diabetes Centre, Leicester General Hospital, Leicester, LE5 4PW Email: Ty20@le.ac.uk

${ }^{*}=$ the authors are the writing committee for this paper from the ORIGIN trial investigators 


\begin{abstract}
Aims: To quantify whether insulin therapy, and concomitant weight gain, affects recreational physical activity and TV viewing time using data from the Outcomes Reduction with an Initial Glargine Intervention (ORIGIN) trial.
\end{abstract}

Methods: 12,537 insulin-naïve individuals with dysglycaemia were randomised to receive either basal insulin glargine or standard care and followed for a median of 6.2 years. Complete recreational physical activity and TV viewing time questionnaires across baseline, 2 year follow-up and study end were available for 8,954 participants. Differences between groups at follow-up were assessed by analysis of covariance.

Results: At follow-up, there was no difference in physical activity or TV viewing time between those taking insulin glargine and those receiving standard care, despite body weight increasing by $1.66(7.56) \mathrm{kg}$ in the insulin glargine group and reducing by -0.65 (7.90) $\mathrm{kg}$ in the standard care group $(P<0.001)$. The dose of insulin glargine was not associated with changes in physical activity.

Conclusions: Despite modest weight gain, insulin glargine did not adversely impact recreational physical activity levels within an international cohort with dysglyaemia.

ORIGIN ClinicalTrials.gov number: NCT00069784.

Key words: insulin therapy, physical activity, sedentary behaviour, weight gain 


\section{INTRODUCTION}

Observational research has consistently shown an association between physical activity and the risk of cardiovascular mortality and morbidity in people with dysglycaemia, while intervention research have shown that regular physical activity results in improved glycaemic control in people with diabetes treated with insulin or other glucose lowering therapies [1-3]. Physical activity is therefore considered to be an important therapeutic tool in helping maintain functionality, glycaemic control and low cardiovascular risk in those with type 2 diabetes [4]. Independent of physical activity levels, time spent in sedentary (sitting) behaviours, such as TV viewing, have been associated with an increased risk of mortality and cardiovascular disease and worse metabolic health in the general population and in those with a high risk, or diagnosed, type 2 diabetes [5-7]. Despite this, little is known about the potential impact of commonly used medications on habitual levels of physical activity and sedentary behaviour. This is particularly relevant to therapies that may cause weight gain, such as insulin. The relationship between physical activity, sedentary behaviour and body weight is likely to be bi-directional, with weight gain leading to reductions in levels of physical activity [8-10]. Therefore, it is possible that therapies causing weight gain may also lead to reduced physical activity and increased time spent sedentary. Other factors such as the severity of side effect or the perceived risk of undertaking strenuous movement may further affect levels of physical activity in patients with type 2 diabetes. This hypothesis needs further investigation in order to inform clinical decision making when initiating a new therapy or increasing the dose of an existing therapy.

The aim of this study is to investigate the long-term effect of insulin glargine on levels of recreational physical activity and TV viewing time in a large international study. 


\section{SUBJECTS, MATERIALS AND METHODS}

\section{STUDY DESIGN}

This paper reports data from the insulin arm of the ORIGIN (Outcome Reduction with Initial Glargine Intervention) trial, a multicentre, randomised 2x2 factorial trial designed to investigate the effect of open label insulin glargine and $\omega-3$ fatty acids on cardiovascular morbidly and mortality in 12,537 adults with dysglycaemia recruited between September 2003 and December 2005. The design, CONSORT diagram and primary outcomes from the study have been reported previously [11-13]. In brief, participants were recruited from 40 different countries and included if aged $\geq 50$ years, were at high risk for a CV event and had either impaired fasting glucose (IFG), impaired glucose tolerance (IGT), newly detected or established type 2 diabetes treated with 0 or 1 oral therapies. Participants were followed up for a median of 6.2 years with the trial completed in December 2011.

Participants allocated (1:1) to insulin glargine had it added to their pre-existing glycaemic regimen, and titrated the dose to achieve a self-measured fasting blood glucose of $95 \mathrm{mg} / \mathrm{dl}(5.3 \mathrm{mmol}$ per litre) or less $[11,13]$. Participants allocated to standard care continued their pre-randomisation therapy. Insulin was only considered when maximal doses of two different oral glucose lowering therapies were not sufficient to maintain adequate glucose control. Individuals in both groups received basic lifestyle advice at randomisation and again at subsequent follow-up visits.

\section{PHYSICAL ACTIVITY}

Recreational physical activity was assessed at baseline, 24 months and study end by a modified version of the Minnesota Leisure Time Physical Activity Questionnaire [14]. 
The questionnaire contained a list of 38 common moderate- and vigorous-intensity leisure time physical activities, including walking for exercise, hiking, bicycling, and gardening or yard work. Participants were asked to recall all activities that they had undertaken more than 10 times in the last 12 months, indicate the month or months of the year the activity occurred in, provide the average number of times per month on which the activity was undertaken and the average duration of each bout. Lack of participation in any physical activity more than 10 times in the previous 12 months or participation in activities not listed were also captured. At baseline, 475 (4\%) participants provided information on activities undertaken in addition to those listed; separately listed walking-based activities were included. Each listed activity was assigned an intensity value in METs based on published data [15]. Activities were categorised as walking, other moderate-intensity or vigorous-intensity physical activity. A summary activity score in MET-hr/week was computed for each activity category and for total physical activity.

The method of capturing physical activity in the preceding 12 months employed in this study has been widely used through the Minnesota Leisure Time Physical Activity Questionnaire and the Kuopio Ischaemic Heart Disease Risk Factor 12 Month Physical Activity History questionnaire and has been shown to compare favourably to other questionnaire formats for intra-person variability whilst having similar levels of validity [16-19].

\section{DEMOGRAPHIC, ANTHROPOMETRIC AND BIOCHEMICAL MEASURES}

Demographic (geographical region, age, sex, employment status, education status, smoking status) anthropometric (weight, height, waist circumference, blood pressure), biochemical (fasting glucose, 2-hour post-challenge glucose, $\mathrm{HbA1c}$, total cholesterol, HDL-cholesterol, triglycerides, urine albumin to creatinine ratio), medication status, 
dysglycemia status, and history of cardiovascular disease were captured at baseline using standardised procedures [13].

\section{STATISTICAL ANALYSIS}

Study participants with physical activity data available at all three time points (baseline, 24 months and study end) were included in the analysis for physical activity. Similarly those with complete TV viewing data were included in the analysis for TV viewing.

Differences between insulin glargine treatment and standard care in levels of total moderate-to-vigorous physical activity (MVPA), vigorous-intensity physical activity, walking activity, other moderate-intensity physical activities and TV viewing time were assessed at 24 months and study end through analysis of covariance (ANCOVA) modelling that adjusted for baseline level, $\omega-3$ fatty acid allocation, baseline diabetes status, and the presence or absence of a history of a cardiovascular event. Interaction analysis was undertaken to investigate whether sex or glycaemic status at baseline (IGT/IGR vs. type 2 diabetes) modified the effect of insulin glargine on physical activity levels.

In order to further explore the impact of insulin dose on physical activity levels, data from the insulin glargine group was used to undertake a repeated measures ANCOVA; measures of physical activity and TV viewing at 24 months and study end were used as dependant variables with the last recorded insulin dose preceding the clinical visit at 24 month and study end used as a time varying independent variables. Insulin doses were assessed at a median of 123 days (IQR 119, 128) before the assessment of physical activity and TV viewing at 24 months and 54 days $(36,64)$ at study end, thus the analysis investigates the effect of insulin dose on subsequent changes to physical activity and TV viewing. Analysis for physical activity at follow-up was adjusted for 
baseline physical activity and sex, along with the following additional baseline factors: age, region, statin use, weight, fasting blood glucose, cholesterol, triglycerides, and urine albumin to creatinine ratio. Analysis for TV viewing time was adjusted for: baseline TV viewing time, gender, age, region, statin use, weight, BMI, fasting blood glucose, HbA1c, cholesterol, and triglycerides. In addition, both models were further adjusted for changes to body weight to assess whether any observed associations were attenuated by weight gain. Baseline covariates were chosen as factors associated with insulin dose at 24 months, adjusted for baseline total physical activity (physical activity factors) or baseline TV viewing time (TV viewing time factor). Interaction analysis was undertaken to investigate whether glycaemic status at baseline or sex modified the results of the regression analysis.

All analysis was 2-sided; $p<0.05$ was considered significant. Adjustment was not made for multiple testing with findings interpreted in relation to the overall pattern of results. Results are presented as means (SD), unless specified otherwise.

\section{RESULTS}

In total, 8954 participants ( $71 \%$ of those randomised) had complete physical activity data and were included for the physical activity analysis; 9639 (77\%) had complete TV viewing data. Differences in baseline characteristics between those included and excluded for physical activity data are presented in Supplemental Table S1; the only difference was that $35.4 \%$ of those included were female compared to $33.9 \%$ of those excluded. 
The study characteristics, baseline physical activity levels and TV viewing time of those with complete physical activity data, stratified by study group, are displayed in Table 1.

Of those randomised to the insulin glargine group and included in this study, $94 \%$ were compliant to their insulin regime after 2 years and $85 \%$ by study end. At 24 months the median insulin glargine dosage was 24 units (IQR 14, 42) increasing to 29 units (14, 47) by study end. After 24 months 3\% participants in the standard care group were receiving insulin therapy which increased to $11 \%$ by the study end. Over the course of the study body weight increased by 1.66 (SD 7.56) $\mathrm{kg}$ in the insulin glargine group and reduced by $0.65(7.90) \mathrm{kg}$ in the standard care group $(\mathrm{P}<0.001$ for difference between groups).

Table 2 shows the change to recreational physical activity levels and TV viewing time from baseline for both groups at 24 months and study end and the adjusted effect of the insulin glargine group compared to standard care. There was no difference between groups in change in recreational physical activity levels or TV viewing time by study end, although there was a slight increase in walking levels reported at 24 months in the insulin glargine group compared to the standard care group of 0.66 ( $95 \% \mathrm{Cl}$, $0.01,1.31) \mathrm{MET}$-hrs/week. Interaction analysis revealed results were not modified by sex or baseline glycaemic status at either 24 months or study end $(p>0.05$ for all interactions).

Table 3 shows the associations between insulin dose and recreational physical activity levels in the insulin glargine group. Insulin dose was not associated with total, vigorousintensity, moderate intensity, or walking activity. However, there was a weak association for TV viewing whereby each unit difference in insulin dose was associated with a $0.7(95 \% \mathrm{Cl} 0.1,1.3) \mathrm{min} /$ week difference in TV viewing time. However, the 
association with TV viewing disappeared after further adjustment for change in weight (Table 3). Association for insulin dose with recreational physical activity and TV viewing were not modified by sex or glycaemic status ( $p>0.05$ for all interactions).

\section{DISCUSSION}

This study suggests that treatment with insulin glargine does not affect recreational physical activity levels or TV viewing time compared to standard care treatment largely based on oral glucose lowering therapies. To our knowledge this is the first study to investigate the impact of insulin therapy on physical activity levels and TV viewing.

While the initiation of insulin therapy in type 2 diabetes is known to cause weight gain, the effect on related lifestyle factors has not been investigated [20]. This is an important limitation as weight gain has been shown to reduce physical activity levels [8-10], making it possible that weight gained through insulin therapy results in further deleterious effects on lifestyle behaviours. However, despite a modest level of weight gain in the insulin glargine group compared to standard care over the course of the trial (around $2 \mathrm{~kg}$ ), this study did not find evidence to support this hypothesis. Specifically, patients randomised to receive insulin glargine had similar levels of physical activity and TV viewing time at follow-up as those receiving standard care. Further analysis confirmed that the dose of insulin glargine was not associated with reduced physical activity. Small increases in TV time were observed with higher insulin doses although differences were unlikely to be clinically meaningful; more than an 80 unit difference in insulin glargine dose was needed for a 60 minute difference in TV viewing per week. 
It is possible that the amount of weight gain seen in this study was insufficient to adversely affect physical activity levels. In previous observational analyses, a modest weight gain of between 0.5 to $2.0 \mathrm{~kg}$ per year was associated with an increased likelihood of becoming physically inactive and an experimental study revealed that 3.6 $\mathrm{kg}$ weight gain over the short term was associated with a reduction in walking distance in both obese and lean individuals $[8,10]$. However our results from a randomised trial over the longer term are consistent with another large international trial in people with impaired glucose tolerance which found that changes to weight over a 6 year period were not associated with changes to objectively assessed daily ambulatory activity [21]. It also remains a possibility that the effect of weight gain was modified by other concomitant effects of insulin glargine, for example improved quality of life and treatment satisfaction which may offset the potential for deleterious effects of weight gain on health behaviour [22-25].

The major strength of the this study was the randomised design; previous studies looking at the relationship between weight gain and physical activity levels have relied on observation or short term experimental studies. Other strengths included the large international cohort, and rigorously measured insulin adherence with both medium and long-term follow-up. While investigating a specific, commonly used, long acting insulin is an additional strength, the potential lack of generalizability to other insulin regimes is a limitation. This is particularly important in relation to weight gain. Longer acting insulins are known to confer lower risk of hypoglycaemia and result in less weight gain than other short, biphasic or intermediate acting insulins [26-28]. Therefore it is possible that the effects of other commonly used insulin regimes on physical activity levels may be more prominent than those observed in this study. The study population, which included individuals with prediabetes, newly diagnosed or well controlled type 2 
diabetes, is also unlikely to be representative of patients initiating insulin therapy within routine clinical care; conversely it may be viewed as clinically reassuring that starting early initiation of basal insulin does not adversely affect recreational physical activity levels. Furthermore, this study was limited to participants who completed the 24 month and final study visit; although there was no meaningful difference at baseline between those that were included and excluded in this analysis, it is possible that the exclusion of participants unable to attend follow-up visits increased the likelihood of a null result. Another important limitation is the use of self-reported physical activity levels which have limited validity and high levels of error [29]. However, the sample size and study design may have mitigated this limitation. Specially, by using physical activity as a dependant rather than independent variable, results were at lower risk of regression dilution and the increased variation caused by random error was countered by the large sample size, thus reducing the risk of a type 2 error [30]. Nonetheless, the effect of insulin glargine on physical activity may have been underestimated. In addition, as levels of reported physical activity are dependent on the type of questionnaire used, with both higher and lower self-reported physical activity levels observed in similar populations[31,32], we were not able to assess the generalisability of physical activity levels within ORIGIN.

In conclusion, insulin glargine therapy did not adversely affect recreational physical activity levels or TV viewing in people with dysglycaemia. Whether these results are generalizable to shorter acting insulin therapies, populations with worse glycaemic control, or other glucose lowering medications that cause weight gain remains unclear.

\section{ACKNOWLEDGEMENTS}


MJD and TY are supported by the NIHR Leicester Biomedical Research Centre. The views expressed are those of the authors and not necessarily those of the NHS, the NIHR or the Department of Health.

\section{FUNDING}

The ORIGIN trial was funded by Sanofi. The funders had no role in the analysis or interpretation of the data presented in this manuscript.

\section{AUTHORSHIP CONTRIBUTIONS}

Authors: TY, MJD and HCG contributed to the design of the data analysis. HJ undertook the statistical analysis and had access to the data. MJD and HDG oversaw data collection and conduct of the trial. TY undertook multiple drafts of the manuscript. All authors aided interpretation of data and revised the manuscript across multiple drafts for important intellectual content.

\section{CONFLICT OF INTEREST STATEMENT}

M.J.D. has attended advisory panels for Novo Nordisk, Novartis, Sanofi, Eli Lilly \& Co., AstraZeneca, Boehringer Ingelheim, Omnia-Med, Janssen, and Merck Sharp \& Dohme; has attended speakers' bureaus for Novo Nordisk, Sanofi, Eli Lilly \& Co., Merck Sharp \& Dohme, AstraZeneca, Mitsubishi Tanabe Pharma Corp., and Boehringer Ingelheim; has acted as consultant for Novo Nordisk, Sanofi, Eli Lilly \& 
Co., and Merck Sharp \& Dohme; and has received research support from Novo Nordisk, Novartis, Eli Lilly \& Co., and Merck Sharp \& Dohme.

G.A.S. has received research support from Novo Nordisk and performed advisory board activities with AstraZeneca/Bristol-Myers Squibb, Medtronic, Lilly, MSD, Novo Nordisk, Novartis, Daiichi Sankyo Boehringer Ingelheim, and Sanofi.

S.S. has acted as advisory board member and speaker for Novartis, Novo Nordisk, Eli Lilly and Company, Merck Sharp \& Dohme, Janssen, and Bristol-Myers Squibb and as a speaker for Novo Nordisk, Eli Lilly and Company, sanofi-aventis, GlaxoSmithKline, and AstraZeneca and has received grants from Novo Nordisk, Eli Lilly and Company, sanofi-aventis, AstraZeneca, and Bristol-Myers Squibb.

H.C.G has received consulting fees from Sanofi, Novo Nordisk, Lilly, AstraZeneca, Abbot, Roche, Amgen, Boehringer Ingelheim, Kaneq Bioscience, and GlaxoSmithKline; lecture fees from Sanofi, Abbot; Astra Zeneca and Berline Chemie; and support for research or continuing education through his institution from Sanofi, Lilly, Merck, AstraZeneca, Novo Nordisk, and Boehringer Ingelheim.

All remaining author have nothing to declare

\section{REFERENCES}

(1) Umpierre D, Ribeiro PA, Kramer CK, Leitão CB, Zucatti AT, Azevedo MJ, et al. Physical activity advice only or structured exercise training and association with $\mathrm{HbA} 1 \mathrm{c}$ levels in type 2 diabetes: a systematic review and meta-analysis. JAMA. 2011;305:1790-1799.

(2) Balducci S, Zanuso S, Cardelli P, Salerno G, Fallucca S, Nicolucci A, et al. Supervised exercise training counterbalances the adverse effects of insulin therapy in overweight/obese subjects with type 2 diabetes. Diabetes Care. 2012;35:39-41. 
(3) Yates T, Haffner SM, Schulte PJ, Thomas L, Huffman KM, Bales CW, et al. Association between change in daily ambulatory activity and cardiovascular events in people with impaired glucose tolerance (NAVIGATOR trial): a cohort analysis. The Lancet. 2014;383:1059-1066.

(4) Colberg SR, Sigal RJ, Fernhall B, Regensteiner JG, Blissmer BJ, Rubin RR, et al. Exercise and type 2 diabetes: the American College of Sports Medicine and the American Diabetes Association: joint position statement. Diabetes Care. 2010;33:e147-67.

(5) Henson J, Yates T, Biddle S, Edwardson CL, Khunti K, Wilmot E, et al. Associations of objectively measured sedentary behaviour and physical activity with markers of cardiometabolic health. Diabetologia. 2013;56:1012-1020.

(6) Cooper A, Sebire S, Montgomery A, Peters T, Sharp D, Jackson N, et al. Sedentary time, breaks in sedentary time and metabolic variables in people with newly diagnosed type 2 diabetes. Diabetologia. 2012;55:589-599.

(7) Wilmot E, Edwardson C, Achana F, Davies M, Gorely T, Gray L, et al. Sedentary time in adults and the association with diabetes, cardiovascular disease and death: systematic review and meta-analysis. Diabetologia. 2012;55:2895-2905.

(8) Golubic R, Ekelund U, Wijndaele K, Luben R, Khaw K, Wareham NJ, Brage S. Rate of weight gain predicts change in physical activity levels: a longitudinal analysis of the EPIC-Norfolk cohort. Int J Obes. 2013;37:404-409.

(9) Ekelund U, Brage S, Besson H, Sharp S, Wareham NJ. Time spent being sedentary and weight gain in healthy adults: reverse or bidirectional causality? Am J Clin Nutr. 2008;88:612-617.

(10) Levine JA, McCrady SK, Lanningham-Foster LM, Kane PH, Foster RC, Manohar $\mathrm{CU}$. The role of free-living daily walking in human weight gain and obesity. Diabetes. 2008;57:548-554.

(11) Gerstein HC, Bosch J, Dagenais GR, Díaz R, Jung H, Maggioni AP, et al. Basal insulin and cardiovascular and other outcomes in dysglycemia. N Engl J Med. 2012;367:319-328.

(12) ORIGIN Trial Investigators, Bosch J, Gerstein HC, Dagenais GR, Diaz R, Dyal L, et al. N Engl J Med. 2012;367:309-318.

(13) ORIGIN Trial Investigators. Rationale, design, and baseline characteristics for a large international trial of cardiovascular disease prevention in people with dysglycemia: the ORIGIN Trial (Outcome Reduction with an Initial Glargine Intervention). Am Heart J. 2008;155:26. e1-26. e13.

(14) Taylor HL, Jacobs DR, Schucker B, Knudsen J, Leon AS, Debacker G. A questionnaire for the assessment of leisure time physical activities. J Chronic Dis. 1978;31:741-755. 
(15) Ainsworth BE, Haskell WL, Herrmann SD, Meckes N, Bassett DR,Jr, TudorLocke C, et al. 2011 Compendium of Physical Activities: a second update of codes and MET values. Med Sci Sports Exerc. 2011;43:1575-1581.

(16) Lakka TA, Salonen JT. Intra-person variability of various physical activity assessments in the Kuopio Ischaemic Heart Disease Risk Factor Study. Int $\mathbf{J}$ Epidemiol. 1992;21:467-472.

(17) Richardson MT, Leon AS, Jacobs DR, Ainsworth BE, Serfass R. Comprehensive evaluation of the Minnesota leisure time physical activity questionnaire. J Clin Epidemiol. 1994;47:271-281.

(18) Jacobs DR,Jr, Ainsworth BE, Hartman TJ, Leon AS. A simultaneous evaluation of 10 commonly used physical activity questionnaires. Med Sci Sports Exerc. 1993;25:81-91.

(19) Prince SA, Adamo KB, Hamel ME, Hardt J, Connor Gorber S, Tremblay M. A comparison of direct versus self-report measures for assessing physical activity in adults: a systematic review. Int J Behav Nutr Phys Act. 2008;5:56-5868-5-56.

(20) Leslie WS, Hankey CR, Lean ME. Weight gain as an adverse effect of some commonly prescribed drugs: a systematic review. QJM. 2007;100:395-404.

(21) Preiss D, Thomas LE, Wojdyla DM, Haffner SM, Gill JM, Yates T, et al. Prospective relationships between body weight and physical activity: an observational analysis from the NAVIGATOR study. BMJ Open. 2015;5:e0079012015-007901.

(22) Swinnen SG, Dain MP, Aronson R, Davies M, Gerstein HC, Pfeiffer AF, et al. A 24-week, randomized, treat-to-target trial comparing initiation of insulin glargine once-daily with insulin detemir twice-daily in patients with type 2 diabetes inadequately controlled on oral glucose-lowering drugs. Diabetes Care. 2010;33:1176-1178.

(23) Gerstein H, Yale J, Harris S, Issa M, Stewart J, Dempsey E. A randomized trial of adding insulin glargine vs. avoidance of insulin in people with Type 2 diabetes on either no oral glucose-lowering agents or submaximal doses of metformin and/or sulphonylureas. The Canadian INSIGHT (Implementing New Strategies with Insulin Glargine for Hyperglycaemia Treatment) Study. Diabetic Med. 2006;23:736-742.

(24) Shah S, Zilov A, Malek R, Soewondo P, Bech O, Litwak L. Improvements in quality of life associated with insulin analogue therapies in people with type 2 diabetes: results from the A 1 chieve observational study. Diabetes Res Clin Pract. 2011;94:364-370.

(25) Vinik Al, Zhang Q. Adding insulin glargine versus rosiglitazone: health-related quality-of-life impact in type 2 diabetes. Diabetes Care. 2007;30:795-800.

(26) Rosenstock J, Schwartz SL, Clark CM,Jr, Park GD, Donley DW, Edwards MB. Basal insulin therapy in type 2 diabetes: 28 -week comparison of insulin glargine (HOE 901) and NPH insulin. Diabetes Care. 2001;24:631-636. 
(27) Raskin P, Allen E, Hollander P, Lewin A, Gabbay RA, Hu P, et al. Initiating insulin therapy in type 2 Diabetes: a comparison of biphasic and basal insulin analogs. Diabetes Care. 2005;28:260-265.

(28) Holman RR, Thorne KI, Farmer AJ, Davies MJ, Keenan JF, Paul S, Levy JC. Addition of biphasic, prandial, or basal insulin to oral therapy in type 2 diabetes. $\mathrm{N}$ Engl J Med. 2007;357:1716-1730.

(29) Shephard RJ. Limits to the measurement of habitual physical activity by questionnaires. Br J Sports Med. 2003;37:197-206; discussion 206.

(30) Hutcheon JA, Chiolero A, Hanley JA. Random measurement error and regression dilution bias. BMJ. 2010;340:c2289.

(31) Knowler WC, Barrett-Connor E, Fowler SE, Hamman RF, Lachin JM, Walker EA, et al. Reduction in the incidence of type 2 diabetes with lifestyle intervention or metformin. N Engl J Med. 2002;346:393-403.

(32) Yates T, Edwardson CL, Henson J, Gray LJ, Ashra NB, Troughton J, et al. Walking away from type 2 diabetes: a cluster randomized controlled trial. Diabetic Med. 2017;34:698-707. 
Table 1: Baseline characteristics of study participants with complete physical activity data

\begin{tabular}{|c|c|c|c|c|}
\hline & $\mathbf{N}$ & Overall & Glargine & Standard Care \\
\hline Age & 8954 & $62.75(7.41)$ & $62.78(7.39)$ & $62.71(7.42)$ \\
\hline Female & 8954 & $3171(35.4)$ & $1486(33.3)$ & $1685(37.5)$ \\
\hline \multicolumn{5}{|l|}{ Geographical region } \\
\hline North America \& Australia & 8954 & $1070(11.9)$ & $537(12.0)$ & $533(11.9)$ \\
\hline Mexico \& South America & 8954 & $2602(29.1)$ & $1266(28.4)$ & $1336(29.7)$ \\
\hline Europe & 8954 & $4436(49.5)$ & $2229(49.9)$ & $2207(49.1)$ \\
\hline India & 8954 & $271(3.0)$ & $142(3.2)$ & $129(2.9)$ \\
\hline Asia/Pacific & 8954 & $575(6.4)$ & $289(6.5)$ & $286(6.4)$ \\
\hline Current smoking & 8954 & $1005(11.2)$ & $488(10.9)$ & $517(11.5)$ \\
\hline$>12$ yrs of education & 8953 & $3563(39.8)$ & $1799(40.3)$ & 1764 (39.3) \\
\hline \multicolumn{5}{|l|}{ Employment status } \\
\hline Employed & 8552 & $2853(33.4)$ & 1437 (33.7) & $1416(33.0)$ \\
\hline Unemployed & 8552 & $460(5.4)$ & $231(5.4)$ & $229(5.3)$ \\
\hline Homemaker & 8552 & 996 ( 11.6$)$ & $461(10.8)$ & $535(12.5)$ \\
\hline Never worked & 8552 & $52(0.6)$ & $28(0.7)$ & $24(0.6)$ \\
\hline Retired & 8552 & $4191(49.0)$ & $2105(49.4)$ & $2086(48.6)$ \\
\hline Social security & 8552 & $402(4.7)$ & $201(4.7)$ & $201(4.7)$ \\
\hline \multicolumn{5}{|l|}{ Glycaemic characteristics } \\
\hline Prior diabetes & 8954 & $7287(81.4)$ & $3636(81.5)$ & $3651(81.3)$ \\
\hline New diabetes & 8954 & $554(6.2)$ & $273(6.1)$ & $281(6.3)$ \\
\hline IGT or IFG & 8954 & $1112(12.4)$ & $554(12.4)$ & $558(12.4)$ \\
\hline \multicolumn{5}{|l|}{ Clinical characteristics } \\
\hline Hypertension & 8954 & $7054(78.8)$ & $3516(78.8)$ & $3538(78.8)$ \\
\hline Hyperlipidemia & 8954 & $5987(66.9)$ & $2967(66.5)$ & $3020(67.2)$ \\
\hline $\begin{array}{l}\text { Any albuminuria(measured } \\
\text { or known) }\end{array}$ & 8954 & $1325(14.8)$ & $654(14.7)$ & $671(14.9)$ \\
\hline Previous CV event & 8954 & $5134(57.3)$ & $2594(58.1)$ & $2540(56.6)$ \\
\hline Previous revascularization & 8954 & $3021(33.7)$ & $1517(34.0)$ & $1504(33.5)$ \\
\hline \multicolumn{5}{|l|}{$\begin{array}{l}\text { Glycaemic medication } \\
\text { characteristics }\end{array}$} \\
\hline Metformin & 8954 & $2490(27.8)$ & $1222(27.4)$ & 1268 (28.2) \\
\hline Sulfonylurea & 8954 & $2495(27.9)$ & $1267(28.4)$ & $1228(27.3)$ \\
\hline \multicolumn{5}{|l|}{$\begin{array}{l}\text { CVD medication } \\
\text { characteristics }\end{array}$} \\
\hline Statin & 8954 & $4944(55.2)$ & $2488(55.7)$ & $2456(54.7)$ \\
\hline Beta blocker & 8954 & $4778(53.4)$ & 2377 (53.3) & $2401(53.5)$ \\
\hline Thiazide & 8954 & $1683(18.8)$ & $812(18.2)$ & $871(19.4)$ \\
\hline ACE/ARB & 8954 & $6160(68.8)$ & $3080(69.0)$ & $3080(68.6)$ \\
\hline ASA or Antiplatelet & 8954 & $6235(69.6)$ & $3107(69.6)$ & $3128(69.7)$ \\
\hline
\end{tabular}


Table 1 (Continued)

\begin{tabular}{|c|c|c|c|c|}
\hline & $\mathbf{N}$ & Overall & Glargine & Standard Care \\
\hline \multicolumn{5}{|l|}{$\begin{array}{l}\text { Anthropometric, } \\
\text { biomedical and lifestyle } \\
\text { characteristics }\end{array}$} \\
\hline Weight(kg) & 8953 & $83.58(16.88)$ & $83.51(16.56)$ & $83.64(17.20)$ \\
\hline BMI $\left(\mathrm{kg} / \mathrm{m}^{2}\right)$ & 8950 & $29.88(5.20)$ & $29.74(5.12)$ & $30.01(5.28)$ \\
\hline $\begin{array}{l}\text { Systolic blood pressure } \\
(\mathrm{mmHg})\end{array}$ & 8951 & $145.16(21.23)$ & $145.16(21.02)$ & $145.15(21.43)$ \\
\hline $\begin{array}{l}\text { Diastolic blood pressure } \\
(\mathrm{mmHg})\end{array}$ & 8950 & $84.25(11.81)$ & $84.22(11.77)$ & $84.28(11.86)$ \\
\hline 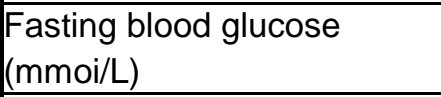 & 8947 & $7.30(1.92)$ & $7.31(1.91)$ & $7.29(1.94)$ \\
\hline $2 \mathrm{hr}$ blood glucose $(\mathrm{mmol} / \mathrm{L})$ & 1647 & $9.78(2.95)$ & $9.74(2.93)$ & $9.81(2.97)$ \\
\hline DCCT HbA1c (\%) & 8865 & $6.49(0.95)$ & $6.50(0.94)$ & $6.47(0.95)$ \\
\hline IFCC HbA1c (mmol/mol) & 8865 & $47(10)$ & $47(10)$ & $47(10)$ \\
\hline Cholesterol (mmol/L) & 8943 & $4.89(1.19)$ & $4.89(1.19)$ & $4.89(1.19)$ \\
\hline HDL Cholesterol (mmol/L) & 8905 & $1.19(0.32)$ & $1.19(0.32)$ & $1.20(0.32)$ \\
\hline Median TG (mmol/L) (IQR) & 8926 & $1.60(1.10,2.21)$ & $1.58(1.11,2.22)$ & $1.60(1.10,2.20)$ \\
\hline $\begin{array}{l}\text { Urine albumin to creatinine } \\
\text { ratio }(\mathrm{mg} / \mathrm{mmol})\end{array}$ & 8749 & $0.53(0.26,1.66)$ & $0.53(0.26,1.68)$ & $0.54(0.26,1.64)$ \\
\hline $\begin{array}{l}\text { Total physical activity } \\
\text { (METs-hrs/week) }\end{array}$ & 8954 & $24.38(33.05)$ & $25.02(34.20)$ & $23.73(31.87)$ \\
\hline $\begin{array}{l}\text { Vigorous intensity physical } \\
\text { activity (METs-hrs/week) }\end{array}$ & 8954 & $5.29(15.72)$ & $5.31(6.57)$ & $5.27(14.84)$ \\
\hline Walking (MET-hrs/week) & 8954 & $11.21(19.33)$ & $11.47(19.44)$ & $10.95(19.23)$ \\
\hline $\begin{array}{l}\text { Other moderate intensity } \\
\text { physical activity (MET- } \\
\text { hrs/week) }\end{array}$ & 8954 & $7.87(19.12)$ & 8.24 ( 20.35) & $7.51(17.82)$ \\
\hline TV viewing time (hrs/week) & 8913 & $19.58(11.58)$ & $19.61(11.43)$ & 19.55 ( 11.74) \\
\hline
\end{tabular}

Parametric data as mean (SD), non-parametric data as median (IQR) and categorical data as number (\%). 
Table 2: Change in physical activity and TV viewing within and between groups at 24 months and study end

\begin{tabular}{|c|c|c|c|c|c|c|}
\hline & \multicolumn{2}{|c|}{ Insulin Glargine } & \multicolumn{2}{|c|}{ Standard care } & \multicolumn{2}{|c|}{ Difference between groups (Insulin Glargine-Standard care)* } \\
\hline & $\mathrm{N}$ & Adjusted Means (SE) & $\mathrm{N}$ & Adjusted Means (SE) & Adjusted Means (95\% Cl) & $\mathrm{p}$ \\
\hline \multicolumn{7}{|c|}{$\begin{array}{l}\text { Total physical activity (MET- } \\
\text { hrs/week) }\end{array}$} \\
\hline Change at 24 months & 4463 & $0.13(0.60)$ & 4491 & $0.00(0.60)$ & $0.13(-0.89-, 1.14)$ & 0.806 \\
\hline Change at study end & 4463 & $-3.40(0.65)$ & 4491 & $-2.68(0.65)$ & $-0.72(-1.82,0.38)$ & 0.199 \\
\hline \multicolumn{7}{|c|}{$\begin{array}{l}\text { Vigorous-intensity physical } \\
\text { activity (MET-hrs/week) }\end{array}$} \\
\hline Change at 24 months & 4463 & $-0.26(0.30)$ & 4491 & $0.23(0.30)$ & $-0.49(-0.99,0.01)$ & 0.054 \\
\hline Change at study end & 4463 & $-1.00(0.27)$ & 4491 & $-0.76(0.27)$ & $-0.24(-0.70,0.21)$ & 0.299 \\
\hline \multicolumn{7}{|c|}{$\begin{array}{l}\text { Walking-intensity physical } \\
\text { activity (MET-hrs/week) }\end{array}$} \\
\hline Change at 24 months & 4463 & $0.61(0.39)$ & 4491 & $-0.05(0.38)$ & $0.66(0.01,1.31)$ & 0.045 \\
\hline Change at study end & 4463 & $-1.32(0.43)$ & 4491 & $-1.33(0.43)$ & $0.01(-0.71,0.74)$ & 0.967 \\
\hline \multicolumn{7}{|c|}{$\begin{array}{l}\text { Other moderate-intensity } \\
\text { physical activity (MET-hrs/week) }\end{array}$} \\
\hline Change at 24 months & 4463 & $-0.18(0.36)$ & 4491 & $-0.17(0.36)$ & $-001(-0.61,0.60)$ & 0.977 \\
\hline Change at study end & 4463 & $-1.02(0.38)$ & 4491 & $-0.55(0.38)$ & $-0.47(-1.11,0.16)$ & 0.144 \\
\hline \multicolumn{7}{|c|}{ TV viewing time (hrs/week) } \\
\hline Change at 24 months & 4808 & $-0.03(0.23)$ & 4831 & $0.19(0.23)$ & $-0.23(-0.61,0.16)$ & 0.254 \\
\hline Change at study end & 4808 & $1.97(0.29)$ & 4831 & $2.17(0.28)$ & $-0.20(-0.67-, 0.28)$ & 0.416 \\
\hline
\end{tabular}

${ }^{*}=$ model adjusted for baseline physical activity, omega 3 allocation, baseline diabetes, and presence or absence of a history of a CV event. 
Table 3: Association of insulin dose with change to physical activity levels and TV viewing time

\begin{tabular}{|c|c|c|c|c|}
\hline & Model 1 & & Model 2 & \\
\hline & $\begin{array}{l}\text { Regression coefficient } \\
(95 \% \mathrm{Cl})^{*}\end{array}$ & $P$ value & $\begin{array}{l}\text { Regression coefficient } \\
(95 \% \mathrm{Cl})^{*}\end{array}$ & $P$ value \\
\hline $\begin{array}{l}\text { Total physical } \\
\text { activity }\end{array}$ & $-0024(-0049,0.001)$ & 0.057 & $-0017(-0043,0.010)$ & 0.221 \\
\hline $\begin{array}{l}\text { Vigorous-intensity } \\
\text { physical activity }\end{array}$ & $-0011(-0021,0.000)$ & 0.052 & $-0010(-0021,0.002)$ & 0.105 \\
\hline Walking Activity & $-0015(-0032,0.002)$ & 0.083 & $-0011(-0029,0.007)$ & 0.244 \\
\hline $\begin{array}{l}\text { Other moderate- } \\
\text { intensity physical } \\
\text { activity }\end{array}$ & $0.002(-0013,0.017)$ & 0.779 & $0.002(-0014,0.018)$ & 0.801 \\
\hline TV viewing & $0.012(0.001,0.022)$ & 0.028 & $0.009(-0002,0.020)$ & 0.107 \\
\hline
\end{tabular}

* $=$ coefficients display the change in physical activity (MET-hrs/week) or TV viewing time (hrs/week) per unit difference in insulin glargine dose

Model 1 adjusted for length of follow-up, baseline value, sex, age geographical region, statin medication status, weight, fasting blood glucose, total cholesterol, triglycerides. Physical activity data additionally adjusted for urine ACR and TV viewing data for HbA1c.

Model 2: additionally adjusted for change in weight 